\title{
“O ZÉ É ASSIM: OU VOCÊ AMA, OU VOCÊ ODEIA": A ATUAÇÃO DA FAMÍLIA JANENE NO MUNICÍPIO DE LONDRINA-PARANÁ ${ }^{1}$
}

\author{
Carla Andréia Alves da Silva Marcelino²
}

- Enviado em 18/04/2016

- Aprovado em 20/05/2016

\section{RESUMO}

O município de Londrina-Paraná, apesar de seus poucos mais de 80 (oitenta) anos, já possui uma extensa rede de famílias, algumas delas interligadas, atuando na política local, estabelecendo grandes teias de nepotismo. Além da família Belinati, a maior e mais atuante na cidade, outra família é muito importante para compreender a história política local: trata-se da família Janene (também grafados como Jannani e Jenani), a qual espraiou-se por todo o Paraná, outros Estados e até mesmo em âmbito nacional. Seu principal membro, José Janene, ficou conhecido como sendo o homem que onde colocou "a sua mão" houve vitória certa, seja na política ou na economia, isto pela rede criada por ele que envolve empreiteiras, políticos, partidos, lavagem de dinheiro, agronegócio, dentre outras atividades lícitas e ilícitas. O objetivo deste artigo é identificar quais foram os capitais que permitiram que a família Janene ocupasse um lugar de destaque na elite político-econômica londrinense e obter poder de controle e articulação da política nacional, já que mesmo após sua morte, José Janene continua no centro das atenções com as denúncias de corrupção presente na mídia nos dias atuais.

Palavras-chave: Janene. Nepotismo. Londrina-Paraná. Poder Político. Parentesco.

\section{INTRODUÇÃO}

A política no Município de Londrina tem sido alvo de estudos sociológicos, despertando grande interesse tanto pela forma peculiar de organização da política local, quanto pelas sucessivas cassações de mandatos de prefeitos. Mas o que efetivamente chama a atenção é a rede de

\footnotetext{
${ }^{1}$ Uma versão preliminar desse trabalho foi apresentada no GT1: INSTITUIÇÕES E PODER: PARENTESCOS E GENEALOGIAS do VII Seminário Nacional de Sociologia e Política da UFPR realizado de 11 a 13 de maio de 2016 em Curitiba.

${ }^{2}$ Graduada em Serviço Social pela Universidade Estadual de Londrina. Especialista em Gestão Pública pelo Instituto Federal do Paraná. Mestre em Sociologia pela Universidade Federal do Paraná. Assistente Social no Governo do Estado do Paraná, com atuação na área de Direitos Humanos e Assistência Social. Endereço eletrônico: carlaalves@onda.com.br
} 
nepotismo, a quantidade de famílias que se estabeleceram no poder local em tão pouco tempo de existência da cidade. Apesar dos pouco mais de 80 anos de existência, Londrina já acumula família que alçaram carreiras e cargos até mesmo em âmbito nacional, tais como os Belinati, Richa, Leite Chaves, Janene e tantos outros.

A família Janene, dentre os seus mais de vinte anos de história política em Londrina, sempre esteve em evidência na mídia, infelizmente ligada a fatos não tão lícitos, sendo citado o seu envolvimento em casos de corrupção envolvendo o antigo banco público do Paraná, o BANESTADO, o caso AMA/COMURB já relatado neste trabalho, o mensalão e agora, na mais recente operação da Polícia Federal, conhecida como Lava-Jato ${ }^{3}$. Importante logo nesse início frisar que a família possui três grafias do sobrenome: Janene, Jannani e Jenani, mas se trata exatamente da mesma família, tendo inclusive irmãos com sobrenomes grafados diferente em razão na naturalidade de cada um (parte nasceu no Líbano e outra no Brasil). Importante esclarecer também que o título deste artigo é uma alusão a uma frase dita pela ex-esposa de José Janene, Sra. Stael, referindo-se ao temperamento difícil e "mandão" do político.

\section{RELAÇÕES DE PODER E PARENTESCO DA FAMÍLIA JANENNE}

Os primeiros Janene chegaram em Londrina na década de 1960, movidos pelo agronegócio, que trouxe também tantas outras famílias para a cidade, como os irmãos Álvaro e Osmar Dias. Abdelkarim Janene e o filho Jamil Janene, pecuaristas criadores de gado nelore, vieram do interior de São Paulo para o Norte do Paraná. Abdelkarim Janene, que também era cafeicultor, foi um dos colonizadores do Município de Colorado, localizado há 150 quilômetros de Londrina, onde comprou terras para a cultura do café na década de 1950.

Esse primeiro Jamil (mais tarde teremos outro familiar de nome homônimo) destacou-se como referência no empreendedorismo no agronegócio, tendo sido presidente da Sociedade Rural do Paraná - SRP por dois mandatos consecutivos (1980-1982 e 1983-1984), período no qual reforçou a importância e a força da pecuária junto com a agricultura, pois assumiu a SRP num período difícil, após a "geada negra" de 1975 que destruiu a cultura do café na região. Esse importante papel de (re)fortalecimento da SRP feito por Jamil Janene está contado na obra de

3 Como Londrina virou o tubo de ensaio que inventou o petrolão. Disponível em <http://www.gazetadopovo.com.br/vida-publica/como-londrina-virou-o-tubo-de-ensaio-que-inventou-o-petrolaodw4t01v0kn0gk7u3049vz52kb?ref=capa-gg>. Acesso em 28 fev. 2014. 
Barbosa (2000), na qual a historiadora faz um resgate da atuação de todos os gestores da SRP até o início dos anos 2000.

Apesar de integrar a classe economicamente dominante local, os Janene entram efetivamente para a política "pelas mãos" da família Belinati, como veremos a seguir, em mais uma clássica conjugação de poder político e poder econômico, transformando-se em um só.

O membro mais famoso da família, José Mohamed Janene, nasceu em Santo Inácio, cidade próxima à Londrina, também no Norte do Paraná, no ano de 1955. Era filho dos imigrantes libaneses Mohamed Assad Janene e Memune Janene, os quais tiveram mais quatro filhos (um falecido), todos eles envolvidos nas teias política e econômica de José Janene.

José trabalhava com o irmão, Faiçal Jannani, que era proprietário de uma empresa de iluminação, a Grupo de Iluminação F. Jannani, a qual desde o final da década de 1980 já vendia seus serviços para várias prefeituras e órgãos públicos da região de Londrina. Após deixar de ser o interlocutor do irmão nos negócios, José Janene cria a sua própria empresa de iluminação, a Eletrojan. Em recente série de reportagens publicadas pelo jornal Gazeta do Povo sobre a participação de londrinenses nos crimes investigados pela operação Lava Jato, foi tornada pública a relação longeva e direta de Janene e Belinati ${ }^{4}$. Porém, se analisarmos a história, a reportagem que tem como título "Aproximação com Belinati garantiu a primeira eleição de Janene”, publicada em 01 de março de 2015, deveria ter seu título invertido, já que antes do fato relatado nessa notícia, foi a aproximação de Belinati com Janene que garantiu a eleição de Belinati para o seu segundo mandato de Prefeito em Londrina. O resto foi apenas retribuição e trocas de favores entre as duas famílias.

Filiado ao PMDB desde 1981, José Janene migrou para o PDT em 1987, mesmo partido em que Belinati estava no período. Foi em 1988 que a aliança Janene - Belinati teve seu início, segundo o blog de comentários de política "Molina... Soltando o Verbo". Afirma o blogueiro Carlos Molina, que a campanha de Belinati para Prefeito em 1988 estava descapitalizada e o também ex-Prefeito Wilson Moreira, do PSDB, estava na frente. Angariando financiadores de campanha, Belinati fecha aliança com Janene, a qual foi recompensada após a vitória de Belinati, com a indicação de cargos do primeiro e segundo escalão no município. Diz o blogueiro sobre a atuação de José Janene nessas eleições:

\footnotetext{
4 Aproximação com Belinati garantiu primeira eleição de Janene. Disponível em <http://www.gazetadopovo.com.br/vida-publica/aproximacao-com-belinati-garantiu-primeira-eleicao-de-janene752 brca3dvhigxz0jsrdj1ikb>. Acesso em 01 mar. 2013.

${ }^{5} \mathrm{O}$ homem que mandava em Londrina. Disponível em <http://molinacuritiba.blogspot.com.br/2010/09/faleceu-josejanene-o-homem-que-mandava.html.> Acesso em 10 dez. 2012.
} 
Ganha a prefeitura e com isso o direito de ratear a administração com seus indicados. [...] A partir daqui é o negociador das tarifas de transporte coletivo com a empresa dos Irmãos Lopes, pois seu indicado é o secretário de Serviços Públicos. [...] Monta dentro da prefeitura de Londrina um esquadrão de apadrinhados, dominando secretarias e órgãos municipais além de contratos de iluminação pública, negócios com concessionárias e até aluguel de arquibancadas de Carnaval e 7 de Setembro. ${ }^{6}$

O Secretário de Serviços Públicos nomeado por Belinati, em 1989, através do Decreto ${ }^{\circ}$ 01/1989, é Eduardo Alonso, apadrinhado de Janene, um dos protagonistas, anos mais tarde, do caso AMA/COMURB, que culminou na cassação de Belinati como prefeito no ano 2000.

Na mesma série de reportagens da Gazeta do Povo citada anteriormente, está relatado que o sonho de Janene era suceder Belinati como Prefeito de Londrina. Em 1990, testou sua popularidade candidatando-se à Deputado Federal pelo PDT, ocasião em que mesmo com o apoio de Belinati, não obteve êxito, pois ficou apenas na suplência e não foi efetivado nenhuma vez naquela legislatura.

Diante dessa realidade, em 1992 desfiliou-se do PDT e migrou para o PP, chegando a presidir o partido no Paraná e a ocupar cargos no diretório nacional. A força do seu poderio econômico lhe rendeu, em 1992, a indicação do seu irmão, Assad Jannani (PDT), para Vice-Prefeito na chapa vitoriosa de Luiz Eduardo Cheida (PT), derrotando a chapa de Wilson Moreira, do PSDB. Na gestão de Cheida, além de Vice-Prefeito, Assad operou como Presidente da SERCOMTEL, empresa pública de telefonia de Londrina. Na gestão de Assad Jannani a empresa fechou um contrato milionário com o Banco Fator, empresa envolvida em escândalos no Município de São Paulo na gestão de Celso Pitta, também do PP.

Em 1994, José Janene consegue o tão almejado cargo de Deputado Federal, com 44.838 $\operatorname{votos}^{7}$, com pouco apoio de Londrina, tendo angariado a maior parte de seus votos em pequenos municípios do Norte do Paraná. Há quem diga que, nessa mesma eleição, a mão poderosa de Janene tenha pesado sobre a decisão de Jaime Lerner em convidar Emília Belinati para ser candidata a Vice-Governadora em sua chapa, pois além da simpatia do povo norte paranaense, a chapa teria também importante apoio financeiro articulado por José Janene.

Durante seu mandato como Deputado Federal, José Janene, conforme indica sua biografia

\footnotetext{
${ }^{6}$ Fonte: Tribunal Superior Eleitoral.

${ }^{7}$ Fonte: Tribunal Superior Eleitoral.
} 
no sítio eletrônico da Câmara dos Deputados ${ }^{8}$, integrou a comissão de Minas e Energia. No período em que esteve em Brasília, Janene teve como seu assessor de imprensa o jornalista e radialista Homero Barbosa Neto, o qual foi prefeito de Londrina no final da década de 2000, também cassado por envolvimento em corrupção e atos ilícitos envolvendo recurso público municipal. Essas relações de Janene acabam dando vazão a afirmações como a do blogueiro Carlos Molina: "Nada acontece em Londrina sem que as mãos sujas de José Janene não se meta (sic) nas inúmeras enrascadas $9 "$.

Em 1996, Janene foi alvo de denúncias e processo criminal respondido em Foz do Iguaçu, num caso de corrupção envolvendo a Companhia de Desenvolvimento de Foz do Iguaçu, autarquia municipal, e a Eletrojan ${ }^{10}$, empresa de iluminação de propriedade de José, a qual foi acusada de superfaturar a venda de postes. Dada a situação, o deputado pediu falência da Eletrojan, fechou a empresa e passou a operar no mesmo ramo com a empresa Mercoluz, também empreiteira de serviços públicos. Nesse mesmo ano Janene volta a operar sua política em Londrina, apoiando Antonio Belinati para o cargo de Prefeito, campanha na qual saíram vitoriosos. Sobre a atuação de José Janene nessa campanha há um relato interessante publicado no jornal online Impacto Paraná, reproduzida no blog "Molina... Solta o Verbo"11:

[...] Faz desistir da campanha a prefeito o então vereador Alex Canziani, pelo PTB, indicando ele para ser o vice-prefeito de Antonio Belinati. José Janene utiliza recursos para custear as despesas já feitas pelo pré-candidato a prefeito e garante Alex na chapa PDT e PTB. Faz uma associação com o candidato do PT a prefeito de Londrina [...], deputado Paulo Bernardo, que começa a atacar o candidato que incomodava aos planos dele: Luiz Carlos Hauly, pelo PSDB. Paulo Bernardo utiliza todo o tempo de televisão e rádio para atacar Hauly e com isso deixar o caminho livre para Antonio Belinati. No segundo turno entre Belinati e Hauly, José Janene consegue viabilizar recursos de Jaime Lerner como governador e mantém uma equipe coordenada pelo próprio chefe de gabinete Gerson Guellmann e o jornalista Fábio Campana. [...] Garante que o PT de Londrina, comandado por Paulo Bernardo, André Vargas e Nedson Micheletti, dê o apoio para a campanha vitoriosa de Antonio Belinati no segundo turno. Garante a eles a manutenção de cargos para petistas no governo de Belinati - como secretaria de Finanças, secretarias especiais, secretaria da mulher além de muitos cargos terceirizados na tal Frente de Trabalho.

$8 \quad$ Biografia.

Disponível

em: <http://www2.camara.leg.br/deputados/pesquisa/layouts_deputados_biografia?pk=97792\&tipo=0.> Acesso em 03 mar. 2015.

${ }^{9} \mathrm{O}$ homem que mandava em Londrina. Disponível em <http://molinacuritiba.blogspot.com.br/2010/09/faleceu-josejanene-o-homem-que-mandava.html.>. Acesso em 10 dez. 2014.

10 Minsitério Público do Paraná pede ação contra Janene. Disponível em <www1.folha.uol.com.br/fsp/brasil/fc160811.htm>. Acesso em 20 dez. 2015.

${ }^{11}$ O homem que mandava em Londrina. Disponível em <http://molinacuritiba.blogspot.com.br/2010/09/faleceu-josejanene-o-homem-que-mandava.html.>. Acesso em $10 \mathrm{dez}$. de 2014. 
O apoio à Belinati foi cobrado a preço caro por José Janene, já que nessa gestão do Poder Executivo municipal, Assad Jannani foi nomeado por Belinati, através do Decreto no 36/1997, para o cargo de Secretário Municipal de Serviços Públicos, secretaria responsável pelas articulações, contratações e concessões de transporte público, coleta de resíduos sólidos, dentre outros. Não por coincidência, no mesmo período, o irmão de José, Faiçal Jannani administrava as empresas Visatec (limpeza pública), Visacon (construtora de obras) e Visamáquinas (aluguel de máquinas e equipamentos), todas prestadoras de serviços da PML. No início de 1999, Assad mudou de pasta, assumindo a presidência da COHAB/LD, permanecendo no cargo por apenas cinco meses, saindo quando Belinati foi afastado devido às denúncias do caso AMA/COMURB. Apesar do pouco tempo no cargo, a atuação de Assad na COHAB/LD lhe rendeu uma condenação judicial em 2014 pelo envolvimento em um caso de irregularidades numa dispensa de licitação envolvendo uma empresa de Foz do Iguaçu ${ }^{12}$.

Com a máquina da Prefeitura de Londrina sob seu controle e o apoio de uma série de Prefeitos de pequenos municípios do Norte do Paraná, em 1998 Janene reelege-se Deputado Federal, pelo $\mathrm{PPB}^{13}$, com 105.230 votos, sendo o segundo mais votado do Estado do Paraná, ficando atrás apenas de Rafael Greca, ex-prefeito de Curitiba ${ }^{14}$. Curioso observar que apesar de Janene ter atuado nos bastidores da política londrinense por tanto tempo, a cidade não era um reduto eleitoral seu, já que dos votos obtidos, apenas 20.000 eleitores eram de Londrina, perfazendo menos de $20 \%$ dos seus votos. Ao verificarmos as suas votações, vê-se que as cidades menores da região Norte do Paraná foram responsáveis pela sua eleição, como Cambé, Ibiporã, Jardim Alegre, Cambará, além de Cornélio Procópio, na qual Janene obteve os votos de cerca de $40 \%$ dos eleitores locais ${ }^{15}$.

Entre os anos de 1999 e 2000, eclode o caso AMA/COMURB em Londrina, carro de corrupção no qual Belinati e seus parceiros políticos estão envolvidos, dentre eles José Janene e o doleiro Alberto Youssef. Diante da inviabilização (momentânea) de Belinati na política local, Janene passa a caminhar por outras sendas, apoiando nas eleições do ano 2000 o candidato Homero Barbosa Neto, do PDT, o qual como já falamos, foi assessor de José Janene nos anos de 1990. Na

\footnotetext{
12 TJ condena ex-diretores da COHAB de Londrina. Disponível em <http://destaknews.com.br/?p=14261 >. Acesso em 7 jun. 2014.

${ }^{13}$ Neste período o PP - Partido Progressista havia se fundido ao PPR - Partido Progressistas Reformador, tornando-se PPB - Partido Progressista Brasileiro em 1995, sigla que foi usada até o ano de 2003, quando o partido voltou a ser PP.

${ }^{14}$ Fonte: Tribunal Superior Eleitoral.

${ }^{15}$ Fonte: Tribunal Superior Eleitoral.
} 
chapa, como parte do acordo, figurou novamente como Vice-Prefeito Assad Jannani. Em disputa contra Nedson Micheletti, companheiro de Janene nas eleições de 1996, a chapa de Barbosa Neto e Jannani foi derrotada. Diz-se na cidade que toda esta manobra de Janene com Barbosa Neto tinha como objetivo primeiro evitar que Luiz Carlos Hauly, do PSDB, inimigo histórico de Janene, ficasse de fora do segundo turno daquelas eleições, objetivo que foi alcançado, para o que contaram com a ajuda de Cheida, agora candidato a prefeito pelo PMDB, que usava o seu horário eleitoral para distribuir ofensas contra Hauly.

Nesse mesmo pleito municipal, mais um membro da família Janene obtém sucesso em um cargo eletivo: Jamil Janene, sobrinho de José, filho de Mohamed Cassin; elegeu-se pelo PDT já no primeiro pleito disputado, com $2.244 \operatorname{votos}^{16}$.

Em 2002, pelo PPB, José Janene busca o seu terceiro mandato, elegendo-se Deputado Federal com 119.501 votos, dos quais apenas 8.671 vieram de eleitores de Londrina, nem 10\% do total de votos obtidos, sendo o seu "curral" eleitoral novamente as pequenas cidades do Norte do Paraná, em especial aquelas do chamado Vale do Ivaí (Ivaiporã, Manoel Ribas, Jardim Alegre, etc.). Tal sucesso nesses pequenos municípios advinha do fato de seus prefeitos trabalharem em prol de Janene nas campanhas, angariando votos. Na maioria delas, a família Janene vendia algo ou prestava algum serviço ao poder público. Nessa eleição chama-nos a atenção o fato de José Janene ter obtido quase 3.000 votos no município da Lapa, cidade da Região Metropolitana de Curitiba, tão distante de Londrina e do Norte do Paraná. As ligações de Jenene com a Lapa já remontam a meados dos anos de 1990, quando teria indicado um "apaniguado da Lapa para a CONAB", vinculada ao Poder Executivo federal, conforme noticia o blogueiro Carlos Molina. Nesse seu terceiro mandato de Deputado Federal, Janene foi líder do PP na Câmara, conforme noticia o sítio eletrônico daquela casa. Na mesma eleição de 2002, tendo Assad Jannani como coordenador de campanha, Janene elege mais um de seus "pupilos", Barbosa Neto, na função de Deputado Estadual. Como parte do acordo, Assad Jannani foi assessor de gabinete de Barbosa Neto na Assembleia Legislativa do Paraná.

Com tentáculos na Câmara Federal, na ALEP, na Câmara de Vereadores de Londrina e com seu companheiro do PT, Paulo Bernardo, na Secretaria Municipal de Finanças de Londrina, Janene reforça a sua influência política. Na gestão de Nedson Micheleti, a exemplo, uma empresa chamada Fóssil venceu o processo licitatório para a coleta de resíduos sólidos (lixo). Anos mais tarde foi amplamente divulgado pela imprensa que essa empresa pertencia a um ex-assessor de Janene e

\footnotetext{
${ }^{16}$ Fonte: Tribunal Regional Eleitoral do Paraná.
} 
tinha como sócio oculto o próprio ${ }^{17}$.

As eleições de 2002 foram as últimas em que Janene obteve êxito, já que a partir de então envolveu-se numa série de denúncias, amplamente divulgadas na imprensa, apontado como um dos principais operadores do chamado "mensalão". Em meio a toda a tormenta, nas eleições de 2004, Janene teria apoiado nos bastidores os três principais candidatos a prefeito de Londrina: Nedson, do PT, que pleiteava a reeleição; Belinati, pelo PSL, seu "eterno" sócio nos negócios políticos; e seu “pupilo" Homero Barbosa Neto, pelo PDT. O objetivo possivelmente era garantir a continuidade de seus contratos ocultos com a Prefeitura de Londrina e não permitir, mais uma vez, a vitória de Hauly, do PSDB. Saiu vitorioso Nedson Micheleti, do PT. Outro vitorioso do pleito de 2004 foi novamente seu sobrinho Jamil Janene, que conseguiu continuar no mandato como vereador, pelo PDT, com $2.649 \operatorname{votos}^{18}$.

Em 2006, quando já estava sendo processado pelos inúmeros casos de corrupção envolvendo o PT e o PP, Janene pede aposentadoria do cargo de Deputado Federal alegando invalidez em razão de doença cardiovascular que tinha, com a qual sofria desde muito novo. A aposentadoria visava à proteção dos seus direitos políticos com uma possível cassação de mandato.

Mesmo "inválido", ocupou cargos no diretório nacional do PP, chegando a ser tesoureiro nacional do partido. Como num efeito dominó, o desgaste de José Janene, envolvido ativamente nos casos de corrupção, afetou outros familiares, visto que seu sobrinho Jamil Janene tentou o cargo de Deputado Estadual no pleito de 2006, pelo PDT, obtendo os parcos 5.574 votos, 3.057 deles obtidos em Londrina. ${ }^{19}$ Vale ressaltar que nessa campanha, José Janene apoiou publicamente Antonio Belinati para Deputado Estadual, não figurando como apoiador público do sobrinho Jamil. O mesmo feito repetiu-se nas eleições municipais de 2008, quando Jamil Janene ficou apenas na suplência do PMDB para a vereança, com $2027 \operatorname{votos}^{20}$. Nessas mesmas eleições de 2008 Janene apoia para a prefeitura Antonio Belinati, pelo PP, sem sucesso, já que o candidato ganha mas não pode assumir porque sua candidatura não havia sido homologada, em fatídica passagem da história política de Londrina.

Desde que seu nome começou a ser ventilado nos esquemas de corrupção, em especial o “mensalão", José Janene passou a ter piorada a sua situação de saúde, falecendo em 2010 vitimado 17 Testemunha explosiva. Disponível em <http://www.istoe.com.br/reportagens/detalhePrint.htm?idReportagem=11213\&txPrint=completo.>. Acesso em 25 ago. 2013.

${ }^{18}$ Fonte: Tribunal Superior Eleitoral.

${ }^{19}$ Fonte: Tribunal Regional Eleitoral do Paraná.

${ }^{20}$ Fonte: Tribunal Regional Eleitoral do Paraná. 
por um acidente vascular cerebral, seguido de parada cardíaca. O jornal Gazeta do Povo, ao noticiar a morte de Janene, afirma que:

Um dos pivôs do escândalo do mensalão, que estourou em 2005, Janene é réu no processo que apura o caso. Ele é suspeito de ter recebido R 4,1 milhões do esquema. Na ação, que corre no Supremo Tribunal Federal, Janene é acusado de formação de quadrilha, corrupção passiva e lavagem de dinheiro. O ex-parlamentar sempre negou as acusações. ${ }^{21}$

Mesmo depois de morto, o nome de Janene continuou a ser citado nos esquemas de corrupção, estando nos dias atuais envolvido diretamente nas acusações de corrupção na Petrobrás, o chamado "petrolão", foco de investigação da operação "Lava-Jato". Conforme delação do exdiretor da Petrobrás, Paulo Roberto Costa, Janene o teria indicado para o cargo no ano de 2004, sendo ele (Janene) o responsável por arrecadar os valores de propina provenientes de contratos da estatal e distribuir entre os demais partícipes, dentre eles outro londrinense, o ex-Deputado Federal André Vargas, do PT. Após a sua morte, foi sucedido na função pelo doleiro Alberto Youssef, também delator do esquema do "petrolão"22.

No ano de 2014 o Ministério Público Federal representou na $13^{\text {a }}$ Vara Federal Criminal contra Meheidin Hussein Jenani, primo de José Janene, Daniele Kemmer Janene, filha de José, e Assad Jannani, também irmão de José, denunciando-os por lavagem de dinheiro obtido por José Janene através do "mensalão". Sua primeira esposa, Stael Fernanda Rodrigues de Lima, também foi investigada pela Delegacia da Receita Federal de Londrina por enriquecimento ilícito (JUSTIÇA FEDERAL DA 4 ${ }^{\mathrm{a}}$ REGIÃO, 2014).

Meheiden, Danielle e um dos filhos de Assad Jannani também foram investigados num suposto sumiço de máquinas pertencentes ao espólio de José Janene, as quais haviam sido compradas através de leasing do Banco do Brasil e deveriam ser retomadas pelo banco, que ao tentar fazê-lo, constatou o desaparecimento destas das dependências da empresa Dunel, administrada pela filha de José, Danielle Janene ${ }^{23}$. Assad, conforme noticiado pela Revista Isto É, também foi investigado por outro crime no mensalão, envolvendo o aluguel de carros para os Correios, pela empresa JN Rent a Car, da qual era sócio oculto ${ }^{24}$.

\footnotetext{
${ }^{21}$ Morre José Janene. Disponível em <http://www.gazetadopovo.com.br/vida-publica/morre-jose-janene-um-dos-pivosdo-escandalo-do-mensalao-28na966oqptaeu9exh3bqo1fy>. Acesso em 25 jul. 2014.

22 Londrinenses se encontram na Lava Jato. Disponível em <http://www.impactopr.com.br/londrinenses-sereencontram-na-lava-jato/>. Acesso em 02 mar. 2015.

${ }^{23}$ Herdeiros de Janene podem ser desmascarados. Disponível em <http://ucho.info/herdeiros-de-jose-janene-podem-serdesmascarados-no-caso-de-participacao-oculta-em-empresa-de-tecnologia.>. Acesso em 14 dez. 2014.

24 Esquema de doleiro também operou nos Correios. Disponível em <http://www.istoe.com.br/reportagens/359698_ESQUEMA+DO+DOLEIRO+OPEROU+NOS+CORREIOS>. Acesso 
Além de todos os casos aqui citados - AMA/COMURB, "mensalão" e "petrolão", a família Janene ainda teve seu nome envolvido em outro famoso escândalo da política paranaense: o caso BANESTADO, no qual juntamente com seu compadre Alberto Youssef, foi acusado de lavar dinheiro recebido ilicitamente através de contas no banco público ${ }^{25}$.

Para além dos nomes e cargos aqui já citados, é possível encontrar alguns outros parentes de José Janene ocupando cargos mais coadjuvantes, tais como Dulcinéia Jannani, esposa de Assad Jannani, que ocupou cargo comissionado na ALEP durante o mandato de Barbosa Neto como Deputado Estadual (2003-2006), ocasião em que foi acusada de ser funcionária fantasma daquela casa legislativa ${ }^{26}$, no mesmo período em que o esposo, como já citamos, foi Chefe de Gabinete de Barbosa. Mehedin Hussein Jenani, primo de José, já citado aqui, e sua esposa, Rosa Alice Valente, ocuparam cargos comissionados na Assessoria Parlamentar de José Janene em Brasília, no seu último mandato na Câmara Federal (2003-2006).

A outra irmã viva de Janene, Soleima Janene Barion, também esteve envolvida nos negócios de José, sendo que ela e o esposo, Jurandir Barion, foram sócios investidores de José Janene na empresa de iluminação Eletrojan. Em reportagem da Folha de São Paulo ${ }^{27}$, Soleima conta que ela e o marido investiram cerca de R $\$ 500$ mil na Eletrojan e contraíram empréstimos de cerca de $\mathrm{R} \$ 400$ mil para a campanha de Janene para Deputado Federal, em 1994, com a promessa de que em vencendo a eleição a Eletrojan ganharia licitações de mais serviços e teria um retorno garantido para todos os sócios. O filho do casal, Aristides Barion, foi o coordenador da campanha em Londrina. O pagamento prometido não veio, Soleima e o esposo perderam todo o patrimônio por falta de pagamento dos empréstimos e romperam relações com José Janene. Sobre o caso, a Folha de São Paulo publicou a seguinte fala de Soleima:

\footnotetext{
"Nós perdemos 23 anos de batalha. Eu perdi muito mais. Perdi sentimentos afetivos que cultivei a vida toda. O Zé é meu irmão caçula, foi aquele irmão que a gente cuida, protege", disse à Agência Folha Solaime Barion, irmã de Janene. Segundo Solaime, sua família foi humilhada. "Era oficial de Justiça todo dia aqui em casa. Minha filha chorava todo dia. O Zé me virou as costas e não ficou para assistir tudo isso". ${ }^{28}$
}

em 01 mar.2015.

${ }^{25}$ Fio solto no caso AMA/COMURB levou ao caso Benestado. Disponível em <http://www.gazetadopovo.com.br/vidapublica/fio-solto-do-escandalo-amacomurb-levou-ao-caso-banestado-dztgc7o8fhorfn8cbp5zlp2rf $>$. Acesso em 28 fev.2015.

${ }^{26}$ Esposa de Assad faria assessoria para Barbosa “em casa”. Disponível em <http://www.bonde.com.br/?id_bonde=1-3-786-20090630.> Acesso em 01 mar. 2015.

${ }^{27}$ Família cobra dívida de deputado na justiça. Disponível em <http://www1.folha.uol.com.br/fsp/brasil/fc160807.htm.> Acesso em 23 fev. 2015.

${ }^{28}$ Família cobra dívida de deputado na justiça. Disponível em <http://www1.folha.uol.com.br/fsp/brasil/fc160807.htm.. 
Sobre a esposa de Janene, Stael, esta sempre esteve nos bastidores e teve seu nome envolvido em várias investigações e ações ligadas à movimentação ilegal de recursos e lavagem de dinheiro. Janene separou-se dela em 2008. Stael Fernanda também está citada na operação LavoJato, pois conforme noticiou a imprensa, investigou-se que ela estava cobrando de Alberto Youssef valores voluptuosos em dinheiro que estariam em uma conta oculta de José Janene no exterior, da qual Youssef teria "se apossado" após a morte dele ${ }^{29}$. Stael chegou a ser ventilada como candidata a Deputada Federal, pelo PP, em 2010, mas declinou a pedido do ex-marido, ainda antes da morte dele $^{30}$.

Atualmente, a família Janene ainda se mantém no poder, já que Jamil Janene, sobrinho de José, voltou a vencer uma eleição, em 2012, com 3.164 votos. Seguindo os passos do tio, Jamil filiou-se no PP e já desponta como uma liderança local do partido, sendo o líder do partido na câmara (na verdade, Jamil é o único do PP na atual legislatura) e o líder da oposição ao atual prefeito, Alexandre Kireff, na gestão em curso (2012-2016).

O poderio da família Janene também se estendeu às duas principais organizações de Londrina: Sociedade Rural do Paraná - SRP e Associação Comercial e Industrial de Londrina ACIL. Na ACIL foi Assad Jannani que representou a família, ocupando uma diretoria entre os anos de 1995-1996 (ACIL, 2007), na gestão de Francisco Negri Filho, empresário do ramo imobiliário. O mesmo Jamil Janene citado no início deste item, além de presidente da SRP, ocupou também os cargos de $1^{\circ}$ Secretário (1966-1968), Diretor do Departamento de Cereais (1968-1969), $1^{\circ}$ VicePresidente (1976-1978), 2 Vice-Presidente (1978-1980, 1988-1990), Diretor sem Pasta (1984-1986, 1986-1988), membro nato do Conselho Deliberativo (1990-1992), membro do Conselho de Administração (2004-2006); seu pai, Abdelkarim Janene, foi conselheiro (1966-1968, 1968-1969, 1970-1972), membro suplente da Comissão Fiscal (1974-1976), membro do Conselho Deliberativo (1976-1978, 1978-1980, 1980-1982); Inocêncio Janene, diretor do Departamento Social (19861988). O membro mais contemporâneo da ala da família Janene vinculada ao agrobusiness, é o agropecuarista Marcelo Janene El Kadre, Diretor de Atividades Agrícolas (2002-2003) e de Pecuária (2003-2004) e Diretor Vice-Presidente (2004-2006).

Dono de um grande latifúndio adquirido durante sua história, Janene teve sua fazenda

Acesso em 23 fev.2015.

29 Viúva-bomba assombra PT na CPI da Petrobrás.<http://www.diariodopoder.com.br/noticia.php?i=11682601816. Acesso em 25 fev.2015.

${ }^{30}$ A campanha dos herdeiros do mensalão. Disponível em <http://congressoemfoco.uol.com.br/noticias/a-campanhados-herdeiros-do-mensalao/>. Acesso em 28 fev.2015. 
próxima à Londrina (Fazenda Três Jotas) invadida pelo MST, em 2006, quando o movimento protestava porque Janene supostamente havia comprado as terras com dinheiro do "mensalão". Um grupo de "pistoleiros" armados expulsou os sem-terra da fazenda em 2007, num processo violento de desocupação, o qual Janene negou veementemente que tenha sido a seu mando.

Com fama de mandão, centralizador e obcecado pelo poder e dinheiro, o personagem central da família, José Janene, levou consigo do ápice à derrocada um sem fim de parentes, já citados aqui, além de outros políticos. Em entrevista ao Jornal de Londrina, em 02 de março de 2015, o promotor londrinense Claudio Esteves, que investigou Janene em vários dos casos em que esteve envolvido relata: "Ele se impunha pelo poder, pelo jeito de agir e era arrojado quando desviava dinheiro. Quem queria enriquecer se aproximava dele e ficava sob o guarda-chuva dele". ${ }^{31}$ Na mesma reportagem, sua ex-esposa, Stael, descreve em poucas palavras José Janene: "O Zé era assim: me ame ou me odeie".

Sua história sempre esteve entrelaçada a de Alberto Youssef, com quem tinha relações desde o final dos anos 1990, sempre parceiros nos "negócios" e na vida pessoal. Em 2004 Youssef batizou o filho caçula de Janene e Stael, oficializando aí a relação de compadrio entre ambos, que só se dissolveu com a morte de Janene, de quem Youssef esteve ao lado até a última hora, sendo o responsável por assinar o atestado de óbito e fazer a liberação do corpo no hospital em que Janene morreu em São Paulo ${ }^{32}$.

A morte de Janene ainda gera uma série de controvérsias e confusões. No ano de 2015, deputados da CPI da Petrobrás queriam a exumação do corpo de José Janene devido à notícia amplamente veiculada de que o ex-deputado poderia estar vivo e que sua morte faria parte de um golpe $^{33}$. Tal notícia teve sua origem numa suposta fala que a ex-esposa de Janene, Stael, teria feito, a qual dava a entender que ele estava vivo. A notícia ganhou fôlego porque, ao que constam os registros, ninguém, a não ser Alberto Youssef, teria visto o corpo de Janene. Ao desmentir tal notícia, Stael tornou a história ainda mais nebulosa, pois afirmou que Janene não foi velado e enterrado em um caixão porque era muçulmano e pela sua cultura é enterrado envolto em um tecido, vestindo uma túnica branca. Porém, as fotos do velório veiculadas na imprensa mostram o

\footnotetext{
31 Janene sempre perto do poder. Disponível em <http://www.jornaldelondrina.com.br/londrina/conteudo.phtml?tl=1\&id=1534528\&tit=Janene-sempre-esteve-perto-dopoder.> Acesso em 02 mar. 2015.

32 Janene sempre perto do poder. Disponível em <http://www.jornaldelondrina.com.br/londrina/conteudo.phtml?tl=1\&id=1534528\&tit=Janene-sempre-esteve-perto-dopoder.> Acesso em 02 mar. 2015.

33 CPI da Petrobrás exumará corpo de José Janene por achar que ele pode estar vivo. Disponível em <http://epoca.globo.com/tempo/filtro/noticia/2015/05/cpi-da-petrobras-exumara-corpo-de-jose-janene-por-achar-queele-pode-estar-vivo.html.>. Acesso em 17 abr 2016.
} 
suposto corpo em um caixão, o qual permaneceu por todo o tempo fechado. A filha de Janene, Danielle, também veio a público repudiar a exumação do corpo do pai, alegando que qualquer testemunha que esteve no velório poderia atestar a morte, já que o caixão estava aberto. Nenhuma pessoa presente no velório manifestou-se para confirmar o que disse Denielle. A exumação não foi realizada, pois os deputados desistiram de pedi-la após intervenção da família Janene, estando a dúvida até os dias de hoje pairando no meio político.

\section{CONSIDERAÇÕES FINAIS}

Janene fez parte de um círculo vicioso: investiu dinheiro em política, obteve retorno financeiro da política, investiu mais e obteve mais dinheiro ainda e, na medida em que ganhou mais dinheiro, obteve mais poder político, chegando a ser apontado como "o político que mandou no Brasil", conforme divulgado na imprensa nacional no início do mês de março de 2015. Apesar de ter sido uma liderança do PP por quase toda a sua carreira política, Janene transitou tranquilamente por outros partidos, estando registradas as suas relações com PT, PMDB e PDT. Dizem pela cidade de Londrina que os tentáculos de Janene tenham chegado até o Estado do Mato Grosso e de São Paulo, com empresas que chegaram a prestar serviços para grandes prefeituras, tais como Santo André e Ribeirão Preto, em administrações petistas.

Embora tenha tido frustrado o seu sonho de ser prefeito, Janene "venceu" ao menos cinco eleições consecutivas em Londrina, na qual os seus "apadrinhados" elegeram-se prefeitos da cidade, iniciando com Belinati, em 1988, seguindo até Barbosa Neto, em 2008. Não gozou de popularidade em Londrina, cidade que nunca se fez seu curral eleitoral, mas quem precisa de prestígio e popularidade tendo recursos, compadres, amigos poderosos e influência no alto escalão da política paranaense e brasileira?

\section{REFERÊNCIAS}

ASSOCIAÇÃO COMERCIAL E INDUSTRIAL DE LONDRINA - ACIL. Setenta Anos de Luta. Londrina: ACIL, 2007.

BARBOSA, Maria Lucia Victor. A colheita da vida: resgate histórico da sociedade rural do Paraná. Londrina: Sociedade Rural do Paraná, 2000.

JUSTIÇA FEDERAL DA $4^{\text {a }}$ REGIÃO. $13^{\text {a }}$ Vara Criminal de Curitiba. Autos $\mathbf{n}^{0}$ 504722977.2014.404.7000. Rubens de Andrade Filho, Meheiden Hussein Jenani, Ediel Viana da Silva, Dinorah Abrao Chater, Danielle Kemmer Janene, Carlos Alberto Pereira da Costa, Carlos Alberto Murari, Assad Jannani, Alberto Youssef, Carlos Abib Chater. Instaurado em 11 de julho de 2014. 


\title{
"ZÉ IS LIKE THIS: OR YOU LOVE HIM OR HATE YOU HIM": THE PERFORMANCE OF THE FAMILY JANENE IN LONDRINA-PARANA
}

\begin{abstract}
The city of Londrina, Paraná, despite their limited over eighty (80) years, already has an extensive network of families, some of them interconnected, acting in local politics, establishing large webs of nepotism. Besides the Belinati family, the largest and most active in the city, another family is very important to understand the history of local politics: it is the Janene family (also spelled as Jannani and Jenani), which is spilled over across the Paraná, other states and even nationwide. Its largest member, José Janene, became known as the man who where put "his hand" there was a certain victory, either in politics or the economy, that the network created by him involving contractors, politicians, parties, money laundering, agribusiness, among other licit and illicit activities. The purpose of this article is to identify which were the capital that allowed Janene family occupy a prominent place in the political and economic elite Londrina and get power to control and articulation of national policy, as even after his death, José Janene remains at the heart of attention with this corruption allegations in the media today.
\end{abstract}

Key-words: Janene. Nepotism. Londrina Paraná. Político. Parentesco power. 